\title{
Mulher, mãe e trabalhadora: breve
}

balanço de recentes políticas de conciliação entre trabalho e vida familiar no Brasil / Woman, mother and worker: a brief assessment of recent policies of reconciliation between labour and family life in Brazil

Marina de Carvalho Cordeiro*

Resumo: O objetivo deste artigo é analisar as recentes ações governamentais para o tema da conciliação trabalho-vida familiar no Brasil, e, particularmente, mostrar a importância de instituições destinadas ao cuidado de crianças entre zero e seis anos na inserção e manutenção das mulheres no mercado de trabalho. Discute a relação entre "cuidado com os filhos" e trabalho feminino, reafirmando a importância dos serviços destinados às crianças de primeira e segunda infância na ampliação do tempo disponível das mulheres. A seguir, são apontadas as características da família brasileira com relação às questões de gênero, enfatizando a divisão do trabalho doméstico e, em especial, o cuidado com os filhos. Por fim, analisa ações governamentais recentes, considerando a criação da Secretaria Especial de Políticas para as Mulheres e seus Planos Nacionais, a promulgação da Lei de Diretrizes e Bases da Educação, além de aprovação e vetos de outras propostas.

Palavras-chave: trabalho, maternidade, cuidados, creche.

Abstract: The aim of this paper is to analyse the latest governmental measures related to the issue of the reconciliation between work and family responsabilities in Brazil. Firstly, 
we shall present the discussions on the relationship between child care and women's participation in the labour market, restating the importance of day care institutions for children under six years of age to expand women's available time. Secondly, we shall pinpoint some features of the Brazilian family in regard to gender issues, enphasizing the child care sharing. Finally, we shall address the above-mentioned measures taking into account the creation of the Secretaria Especial de Politicas para Mulheres, its national projects and other measures, such as the implementation of the Lei de Diretrizes e Bases da Educação (a law that establishes guidelines for the national education system) as well as the adoption and veto of other proposals.

Keywords: work, motherhood, care work, day care.

\section{Rompendo o male breadwinner model: implicações na conciliação do trabalho com a vida familiar}

Estudos sobre a família apontam para inúmeros elementos que têm provocado redefinições em sua estrutura e nas dinâmicas conjugais e parentais, tais como a inserção feminina no mercado de trabalho, o controle da reprodução, a regulamentação do divórcio, o aumento da expectativa de vida da população, entre outros. Tais fenômenos estariam impondo à família, como instituição social, o redimensionamento de suas bases, alterando a percepção do ambiente familiar - entendido como espaço de construção de individualidades - e as relações entre as gerações. Aponta-se para o aprofundamento do processo de individualização no interior da família, com um centramento mais radical no indivíduo, tendendo à equalização das posições sociais - ainda que tais mudanças permeiem, de forma diferenciada, os diversos estratos e segmentos sociais (Velho, 2004). Um desses fatores é a entrada e manutenção das mulheres no mercado de trabalho.

Ainda que nunca tenha havido, de fato, um modelo puro de "homem provedor, mulher cuidadora", durante largo período histórico esse modelo estabeleceu a diretriz da divisão sexual do 
trabalho que, considerando as diferenças entre países, classes sociais e momentos da história, descrevia melhor a realidade de inúmeras famílias. O equilíbro entre trabalho e vida familiar era, até as últimas décadas do século 20 , mantido através da domesticidade das mulheres e sua exclusão formal e informal do mercado de trabalho - em alguns países, como na Espanha ${ }^{1}$ e em Portugal ${ }^{2}$, por exemplo, as mulheres estiveram legalmente submetidas aos maridos. ${ }^{3}$ No entanto, a partir da entrada e manutenção das mulheres no mercado de trabalho, deu-se uma ruptura em tal conciliação (ou equilíbrio) entre trabalho e família e novos desafios se impuseram não só às famílias que passaram a ter "dois provedores" mas, também, aos sistemas de bem-estar social que tiveram suas bases postas em questão. Com a erosão, a nível comportamental, do modelo "homem provedor, mulher cuidadora", outros padrões emergiram, com destaque para as famílias monoparentais de chefia feminina - fênomeno marcante, principalmente nos países da América Latina - e para as famílias com "dois provedores". ${ }^{4}$ Logo, tais sistemas, que tinham este contrato sexual como modelo, passaram a ser questionados pelos movimentos feministas e impactados pelas próprias alterações comportamentais da população. ${ }^{5}$

1 Astelarra (2007) resgata o contexto histórico espanhol e afirma que com a morte de Franco (1975),
após 40 anos de ditadura, rompeu-se a ideologia dominante de total subordinação feminina
na qual o homem detinha todo o poder sobre a família, proibindo emprego remunerado de
mulheres casadas, o uso de anticoncepcional (com penalidades para elas e para os médicos que
os prescrevessem), negando direitos legais aos filhos nascidos fora do matrimônio (Astelarra,
2007, p. 59).
2 Portugal, por sua vez, ainda que atualmente possua alto índice de emprego feminino, durante o
regime salazarista (que perdurou até 1974), as mulheres eram legalmente submissas aos maridos e
formalmente impedidas de exercer várias ocupações (Crompton; Lyonette, 2007, p. 105-106).
3 No Brasil também houve discriminação legal do trabalho remunerado e fora do âmbito doméstico
das mulheres e estas dependiam, até a promulgação do Estatuto da Mulher Casada (Lei n. 4.121,
de 27 de agosto de 1962), de autorização do marido para exercê-lo. Enfatizamos que ainda
hoje o tema é motivo de conflito e há homens que buscam, de inúmeras formas, impedir suas
companheiras de exercer trabalho remunerado, o que, por vezes, culmina em violência contra
as mulheres.
4 Jane Lewis (2001) usa o termo one-and-a-half earner, apontando para o fato de que, ainda que
inseridas no mercado de trabalho, as mulheres possuem remunerações menores e continuam
arcando com grande parte do trabalho não-remunerado. Assim, não haveria um adult-worker
model-pressupondo a existência de "adultos individualizados e independentes entre si" - mas
sim um one-and-a-half model.
5 Além das mudanças nas estruturas familiares, outros fatores como o envelhecimento da 
Autores apontam que há, entre os países desenvolvidos, o chamado farewells to maternalism, indicando uma mudança nas políticas públicas, a fim de fornecer suporte ao "trabalho para todos" em lugar de políticas que possibilitem a manutenção das mulheres como cuidadoras em tempo integral. O "maternalismo" (maternalism) indica a construção de discursos e ideologias que exaltam a capacidade feminina em "ser mãe" e aplica à sociedade, como um todo, os valores de "cuidado" e "moralidade" associados a esse papel. Aponta-se para um paulatino declínio desta ideologia - ainda que esteja presente a nível de prescrição em muitos casos - porém, políticas chamadas women-friendly fazem-se presentes em muitos países, focadas mais na habilidade feminina em conciliar trabalho remunerado e cuidados do que numa perspectiva mais ampla de igualdade de gêneros, de inclusão social das mulheres e sua completa cidadania. No entanto, a transição de um sistema baseado no "maternalismo" para outro, pautado na idéia de "emprego para todos", depende largamente da capacidade estatal em suportar atividades destinadas aos "cuidados" e em incentivar o emprego feminino, rompendo barreiras ideológicas ${ }^{6}$ que colocam a mulher como "trabalhadora frágil e menos produtiva", considerando possíveis ausências devido à maternidade e ao cuidado com os filhos.

Os atuais índices de emprego feminino no mundo refletem não só aspirações e mudanças de atitude das próprias mulheres, mas também fatores relacionados à economia. No contexto econômico atual, com altas taxas de desemprego, muitas ocupações oferecem remunerações baixas e a entrada das mulheres na esfera do trabalho remunerado tornou-se fundamental para que as

população, a entrada de outras economias nacionais no mercado mundial e a emergência de novos atores políticos no cenário social, também influenciaram as políticas de bem-estar e seus processos de reformulação.

6 Segundo Laís Abramo (2000, p. 132), entre os empresários e executivos, as mulheres trabalhadoras possuem imagem marcada por mitos e preconceito, sendo freqüentemente associadas a altas taxas de absenteísmo, impontualidade e rotatividade, mesmo sem comprovação empírica de tais afirmações. Os direitos relacionados à proteção da maternidade são também associados a maiores custos da mão-de-obra feminina, ainda que a maior parte desses seja de responsabilidade estatal. 
famílias pudessem aumentar e/ou manter seus rendimentos. ${ }^{7} \mathrm{No}$ contexto contemporâneo, o tema da conciliação entre trabalho e família se faz presente na agenda de discussão em inúmeros países que possuem estratégias diferenciadas e que lhe conferem legitimidade em níveis diversos. Foco de atenção em contexto internacional, esta problemática tem obtido historicamente no Brasil, fraca legitimidade. Porém, recentes avanços nos debates relativos à igualdade de gênero no País podem indicar uma abrangência maior do debate sobre o tema na esfera pública. De acordo com Esping-Andersen (2002), em toda a Europa estimulase a atividade remunerada de mulheres e mães, mesmo quando seus filhos ainda são pequenos, e a conciliação trabalho-vida familiar é prioridade como novo programa na União Européia. Argumentase que tal prática incentivaria a ampliação de empregos a fim de atender às exigências dos cuidados e dos trabalhos domésticos, anteriormente realizados (gratuitamente) pelas mulheres; além disso, os rendimentos delas provenientes contribuiriam tanto para a manutenção das famílias acima do nível de pobreza como para o aumento dos custos de previdência social.

\section{Care work: "obrigações" na esfera doméstica e implicações na vida das mulheres}

Os estudos sobre a mulher entraram em voga na academia brasileira através do tema do trabalho feminino, e as pesquisas trilharam novos caminhos quando enfocaram a problemática da articulação entre espaço produtivo (mercado) e reprodutivo (família). Ao longo das décadas de 1970 e 1980 iniciou-se um debate sobre pesquisas estatísticas que buscavam mensurar a atividade econômica feminina, mas essas pesquisas eram tidas como incapazes de realmente apontar a contribuição das mulheres à sociedade. Análises que utilizavam metodologia de orçamento-

Ressaltamos que as taxas de desemprego, de acordo com Abramo (2000, p. 116) são sistematicamente superiores entre as mulheres, entre $10 \%$ e $40 \%$ nos países da América Latina. 
tempo passaram a ser defendidas por pesquisadoras que objetivavam mensurar o volume de trabalho familiar, desenvolvido principalmente por mulheres. Assim, no recenseamento de 1980, importantes contribuições teóricas acerca do conceito de atividade/inatividade econômica foram consideradas, já que a categoria "inativos" obscurecia o considerável volume de trabalho gerado pelos "afazeres domésticos", que mantinham (e ainda mantém) mulheres de várias camadas sociais ocupadas e não eram contabilizadas nos levantamentos. Este debate incidiu sobre a Pesquisa Nacional por Amostra de Domicílios (PNAD) - pesquisa anual, implementada gradativamente pelo Instituto Brasileiro de Geografia e Estatística (IBGE),desde 1967 - e por fim, em 1990, incorporando críticas de estudiosos, houve uma profunda reformulação, com a revisão do conceito de "trabalho".

Neste novo conceito, caracterizaram-se como "trabalho" as atividades remuneradas, não-remuneradas e de produção para próprio consumo e para a família, contribuindo para uma mensuração mais adequada das atividades desempenhadas pelas mulheres. As pesquisas sobre usos do tempo referem-se às atividades desenvolvidas durante um período de tempo (um dia de trabalho, uma semana ou outro período considerado relevante); no Brasil estudos com tal metodologia foram incorporados àqueles sobre o trabalho feminino em 1970, objetivando dar visibilidade à atividade doméstica e valorizá-la, bem como outras formas de atividade que as mulheres desempenhavam sem remuneração (Bruschini, 2007, p. 23-29).

Para a IV Conferência da Mulher em Pequim, em 1995, foi preparado um Relatório de Desenvolvimento Humano (Human Development Report - HDR), com estimativas do tempo gasto por homens e mulheres em atividades mercantis e não mercantis, num conjunto de 31 países. O Relatório, realizado anualmente desde 1990 pelo Fundo das Nações Unidas para o Desenvolvimento, 
define o conceito de desenvolvimento de forma global, tendo como elementos essenciais a igualdade de oportunidades, sua sustentabilidade na passagem entre gerações e o fortalecimento das mulheres. Considerando a equidade de gênero como um dos aspectos centrais deste novo conceito, o Relatório incorporou, desde 1992, as diferenças sexuais na composição do índice e passou a valorizar atividades como criar filhos, cozinhar e cuidar da casa, entre outras. Portanto, uma estimativa dessa contribuição invisível à sociedade passou a ser feita, por meio de pesquisas sobre o tempo gasto por homens e mulheres em atividades mercantis e não mercantis (Bruschini, 2007, p. 29-31).

Os resultados comprovaram que, nos países industrializados, os homens gastavam $66 \%$ do tempo em atividades remuneradas e 34\% em não remuneradas, e nos países em desenvolvimento a relação era de $74 \%$ para $24 \%$; no caso das mulheres, em ambos os tipos de países, a relação praticamente se invertia: elas gastavam 34\% do tempo em atividades remuneradas e $66 \% \mathrm{em}$ não remuneradas (Bruschini, 2007, p. 31). A partir de dados da PNAD (2002), Bruschini realizou uma pesquisa sobre o tempo semanal gasto com afazeres domésticos, analisando-o segundo a presença de filhos, e constatou que "cuidar dos filhos" é uma das atividades que mais consome o tempo disponível das mulheres. Introduzindo na análise a idade das crianças, os dados apontam na mesma direção de muitos estudos de gênero: quanto mais novos, maior é o número de horas de dedicação das mulheres (ver Gráfico 1). Portanto, não só as mulheres (cônjuges e mães) dedicam muito mais de seu tempo disponível para a reprodução social do que os homens, mas também as mães de filhos pequenos possuem tempo semanal de dedicação mais elevado. Segundo Bruschini, tais dados são ainda mais relevantes se considerarmos que são precisamente essas mulheres que compõem a população economicamente ativa com mais vigor, permanecendo mais tempo no mercado de trabalho desde os anos 1980 (Bruschini, 2000 apud Bruschini, 2007, p. 56). 


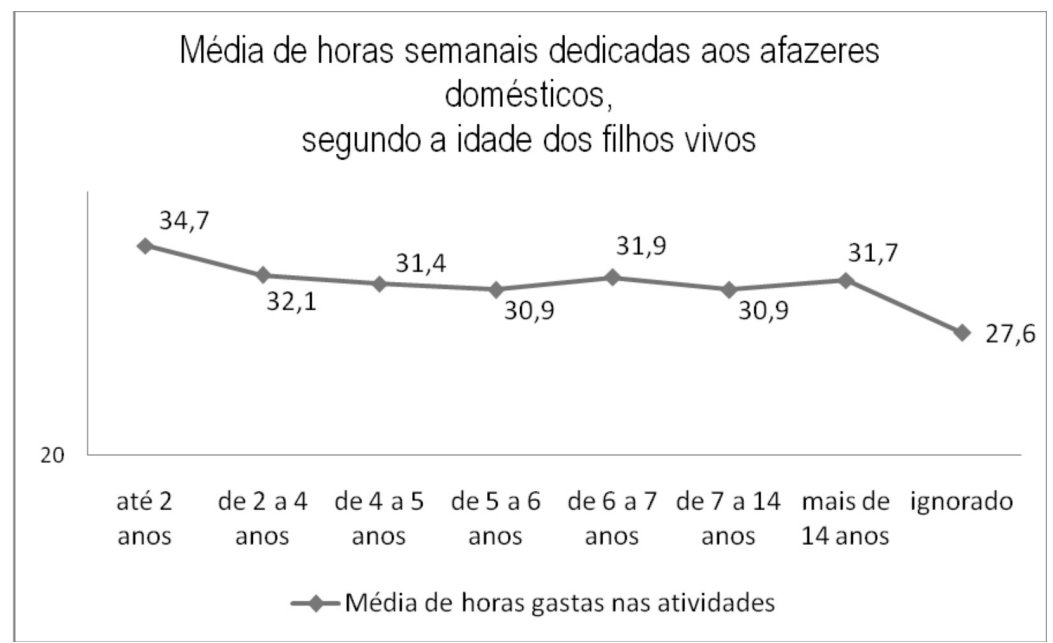

\section{Gráfico 1 - Média de horas semanais dedicadas aos afazeres domésticos, segundo a idade dos filhos vivos}

Fonte: base de dados IBGE, PNAD microdados (Bruschini, 2007, p. 51)

O "cuidado", entendido como "a provisão diária de atenção social, física, psíquica e emocional às pessoas" é realizado predominantemente pelas mulheres, com impactos significativos no desenvolvimento de suas vidas e individualidade (Araújo; Scalon, 2005, p. 22). Tais tarefas consomem grande parte do tempo disponível das mulheres, que é um fator de extrema importância no acesso ao emprego e reconhecimento profissional. Neste contexto, a possibilidade de arcar com as responsabilidades familiares cobradas e o acesso a serviços relacionados à reprodução social - como vagas públicas em creches e pré-escola, por exemplo - tornamse elementos fundamentais para o redimensionamento desse "tempo disponível" (Freire, 2007, p. 14). A ausência de políticas sociais capazes de fornecer uma rede de segurança e atenção neste contexto contemporâneo em que o modelo de família com "dois provedores" torna-se mais freqüente, constante e permanente, acaba gerando um déficit de cuidado, cujo impacto direto é sentido em crianças, enfermos, idosos e, principalmente, nas mulheres; 
em contextos de precariedade socioeconômica, como o brasileiro, esse impacto tende a ser ainda mais forte (Araújo; Scalon, 2005, p. 22-23).

Em pesquisa realizada através de survey "Gênero, trabalho e família em perspectiva comparada", aplicado no ano de 2003 e que abrangeu 195 municípios de 24 Estados, Araújo e Scalon (2005) traçaram um perfil da família brasileira. ${ }^{8}$ A idade média da população da amostra foi de 39 anos, com níveis baixos de instrução, sendo que as mulheres apresentaram percentuais ligeiramente mais elevados de escolaridade a partir do $2^{\circ}$ grau; predominavam as pessoas vivendo conjugalmente em uniões civis ou em uniões de fato, e entre os que se declararam chefes de família, 32\% pertenciam ao sexo feminino (Araújo; Scalon, 2005, p. 27-29). Concentraremos a atenção em aspectos que se referem à dinâmica de conciliação trabalho e família, em especial à divisão do trabalho doméstico, e vale ressaltar que apenas $7,5 \%$ dos entrevistados afirmaram contar com a presença de empregada doméstica - cujo maior percentual foi encontrado nos domićlios com cinco salários ou mais, e naqueles em que havia casais com filhos. Os dados apontaram para uma elevada aceitação do trabalho remunerado como parte constituinte da vida da mulher (com taxas elevadas em ambos sexos), porém, verificou-se, concomitantemente, uma permanência da valorização da domesticidade feminina e seu aspecto maternal, principalmente entre os homens. Há uma tendência a se considerar que a ausência da mulher acarreta carência de afeto, o que, segundo as autoras, pode ser interpretado como maior associação do afeto com a quantidade de tempo dedicado, e menos com sua qualidade. Assim, revela-se a centralidade da maternidade na construção da identidade feminina, principalmente quando há filhos pequenos: ambos os sexos se aproximam na percepção de que as mães não

\footnotetext{
Amostra composta por domicílios de dois mil indivíduos maiores de 18 anos, com controle por setor censitário (urbano e rural) e com cotas para sexo, escolaridade e região. O questionário compunha-se de dois blocos: sobre percepções, extensivo a todos os entrevistados; e outro sobre atitudes práticas na organização da vida cotidiana (Araújo; Scalon, 2005, p. 8).
} 
devem trabalhar em tempo integral nesse momento da vida. O trabalho em tempo parcial, que supõem maiores possibilidades de articulação entre vida familiar e trabalho, é percebido como ideal para parcela significativa das entrevistadas (Araújo; Scalon, 2005, p. 29-31). Os dados coletados expõem uma contradição entre os papéis de "mulher-indivíduo" e "mulher-natureza", revelada não só em termos de valores, mas também no "tempo disponível": ainda que se valorize o trabalho da mulher, mantém-se a idéia de que ela deve garantir o cuidado com os filhos e cumpir com suas funções de "mãe" e "esposa". Tal contradição fica explícita na perceção dos entrevistados quanto à importância dos filhos e da profissão na construção da felicidade ${ }^{9}$; os filhos aparecem como algo que confere sentido à própria existência, bem como o exercício de atividade profissional (ver Tabela 1).

\section{Tabela 1 - Educação dos filhos e exercício de atividade profissional}

\begin{tabular}{c|c|c}
\hline Sexo & $\begin{array}{c}\text { Acompanhar a educação } \\
\text { e o crescimento de uma } \\
\text { criança é a maior alegria } \\
\text { da vida } \\
{[\operatorname{sim}]}\end{array}$ & $\begin{array}{c}\text { Exercer atividade profissional é impor- } \\
\text { tante para as pessoas se sentirem realiza- } \\
\text { das e felizes } \\
\text { [sim] }\end{array}$ \\
\hline F & $96,9 \%$ & $95,1 \%$ \\
\hline $\mathrm{M}$ & $95,5 \%$ & $95,7 \%$ \\
\hline
\end{tabular}

Fonte: Araújo; Scalon, 2005, p. 38.

Logo, as vagas públicas em creches e pré-escolas tornamse de fundamental importância no contexto de uma população que não tem poder aquisitivo para contratar babás, empregadas domésticas ou arcar com os custos de creches privadas. Uma

\footnotetext{
Nesta pergunta solicitou-se aos respondentes que dissessem se "concordavam", "não concordavam nem discordavam" ou "discordavam" das seguintes afirmações: a) acompanhar a educação e o crescimento de uma criança é a maior alegria da vida; b) pessoas que nunca tiveram filhos levam vidas vazias; e, c) exercer atividade profissional é importante para as pessoas se sentirem realizadas e felizes (Araújo; Scalon, 2005, p. 38).
} 
das hipóteses que levantamos aqui é que a carência dessas políticas sociais no Brasil tem fortes influências nas percepções maternalistas e naquelas que sustentam o cuidado com a família como tema privado.

Ainda que haja concordância de que é necessária uma maior participação dos pais na criação dos filhos, os dados comprovam que a divisão sexual do trabalho doméstico continua sendo amplamente dominada pelo padrão tradicional e que a clássica divisão de papéis é bastante enraizada na cultura brasileira. Isto fica claro ao observarmos a divisão do trabalho no cuidado com os filhos, que sugere poucas mudanças; é interessante notar ainda que há um descompasso entre o que cada um dos pares pensa da contribuição do outro (Araújo; Scalon, 2005, p. 44-50). Foram selecionadas algumas respostas do item "divisão no cuidado dos filhos, segundo o sexo", que, dentre os dados disponíveis, nos pareciam mais relevantes para o foco deste trabalho (ver Tabela 2).

\section{Tabela 2 - Divisão das responsabilidades de cuidados com os filhos, segundo sexo}

\begin{tabular}{l|c|c|c|c|c|c}
\hline \multicolumn{1}{c|}{ Sexo } & Fem. & Masc. & Fem. & Masc. & Fem. & Masc. \\
\hline \multicolumn{1}{c}{ Opções } & Eu* & Eu & Juntos & Juntos & $\begin{array}{c}\text { Meu côn- } \\
\text { juge** }\end{array}$ & $\begin{array}{c}\text { Meu } \\
\text { cônjuge }\end{array}$ \\
\hline Dar comida & 84,5 & 8,1 & 6,0 & 19,9 & 2,1 & 65,5 \\
\hline $\begin{array}{l}\text { Dar banho/ } \\
\text { vestir }\end{array}$ & 86,2 & 9,4 & 3,9 & 16,8 & 2,1 & 66,0 \\
\hline $\begin{array}{l}\text { Acompanhar } \\
\text { escolarização }\end{array}$ & 74,1 & 10,6 & 14,7 & 30,5 & 2,9 & 49,6 \\
\hline $\begin{array}{l}\text { Levar filhos ao } \\
\text { médico }\end{array}$ & 77,3 & 9,2 & 16,5 & 36,4 & 1,4 & 48,1 \\
\hline Brincar & 62,5 & 11,0 & 26,0 & 54,9 & 4,8 & 27,1 \\
\hline
\end{tabular}

Fonte: Araújo; Scalon, 2005, p. 49; dados disponíveis em percentagem.

*Somatório das respostas "sempre eu" e "geralmente eu".

** Somatório das respostas "sempre meu cônjuge" e "geralmente meu cônjuge". 
Através da pergunta "quem fica com os filhos menores de 10 anos?”, foi possível identificar que quando não estão na escola, os filhos ficam sob os cuidados da mãe principalmente $(57,6 \%)$, seguido dos avós $(12,1 \%)$ - apoio que, no caso de mulheres sem cônjuge, é ainda mais significativo (20\%) (Araújo; Scalon, 2005, p. 50). Em contextos de precariedade econômica e de restrito amparo social, como os países da América Latina, a solidariedade familiar, representada pela ajuda de tios, avós e/ou irmãos, é de fundamental importância, tomando conta das crianças nos horários em que os pais estão indisponíveis devido ao trabalho e buscando/levando para atividades e/ou para a escola. Arriagada (2007), estudando as relações entre as mudanças ocorridas nas famílias latinoamericanas e sua relação com o trabalho e bemestar na região, reafirma a importância dessa dinâmica e aponta a família como um recurso estratégico de grande valor, cumprindo funções de apoio em situações-problema, como em casos de desemprego, crises econômicas, enfermidade e/ou morte. Diante de uma estreita cobertura social (no trabalho, na saúde e na seguridade social), a família acaba sendo a única instituição capaz de oferecer amparo em casos de eventos traumáticos, auxiliando ainda no cuidado de crianças, idosos, doentes e/ou pessoas portadoras de necessidades especiais (Arriagada, 2007, p. 225).

Pesquisas sobre solidariedade familiar no Brasil corroboram o dito acima e indicam a mesma direção. Peixoto (2005), por exemplo, a partir de dados que se referem ao cuidado com as crianças desse mesmo survey, aponta que os avós (e principalmente as avós) são essenciais na divisão das tarefas domésticas, principalmente nas chamadas "ajudas de subsistência" (Pitrou apud Peixoto, 2005, p. 228), características das camadas populares. De acordo com tais dados, os avós auxiliam em atividades desempenhadas em algumas horas do dia ou nos fins de semana - ainda que haja avós que de fato "criem" os netos, supondo um contato mais contínuo em tarefas como "levar à escola", "acompanhar nas atividades escolares" e "levar ao médico", além de ficarem com as crianças 
até os pais chegarem do trabalho, já que a maioria das instituições escolares funciona apenas em tempo parcial (p. 231-232).

Enfim, no Brasil, são as mulheres que arcam com o ônus do trabalho doméstico ${ }^{10}$ e o "cuidado" continua sendo tratado como um problema privado e de responsabilidade feminina. Ainda que seja possível afirmar que as relações de gênero na família brasileira mudaram se comparadas com algumas décadas atrás, o padrão de domesticidade, que confere desvantagens às mulheres na vida social em geral, ainda é predominante. Ressaltamos que, no Brasil, tais observações precisam ser consideradas com mais rigor na formulação de políticas públicas destinadas aos cuidados, especialmente no que se refere aos serviços destinados ao cuidado de crianças de primeira e segunda infância.

\section{Políticas sociais destinadas ao care work no Brasil}

Inúmeros autores que tratam das relações entre políticas públicas, trabalho e família apontam para a importância de políticas voltadas para o fornecimento de opções de cuidados com crianças, sejam eles fornecidos pelo mercado ou pelo Estado, diante das alterações na composição das famílias modernas (Sorj; Fontes; Machado, 2007, Arriagada, 2007, Esping-Andersen, 2002, Lewis, 2001, Jenson, 1997, Gornick; Meyers, 2007). Sorj, Fontes e Machado (2007) em estudo sobre o tema no Brasil, com base em dados da PNAD (dados de 1992 a 2005), apontam que este possui fraca legimitimidade social e política: o acesso às creches é bastante limitado, apesar de seu crescimento recente, e, no ano de 2001, apenas em 39\% dos domicílios as crianças até seis anos frequentavam a creche e pré-escola, ou seja, a maioria das famílias (61\%) não contava com tal tipo de suporte.

A sensilibilidade da participação feminina no mercado de trabalho ao tipo de família na qual está inserida e à disponibilidade

\footnotetext{
${ }^{10}$ A média de horas gastas por semana com trabalho doméstico é 17,33 para homens e 37,37 para mulheres (Araújo; Scalon, 200, p. 55).
} 
de suporte de cuidados são fatores que reforçam ainda mais a importância de tais políticas. Em estudo recente, Sorj (2006) aponta que enquanto a taxa de participação dos homens no mercado de trabalho independe da estrutura familiar e nunca se mantém abaixo de $84,7 \%$, no caso feminino, dependendo do tipo de família, pode variar entre os extremos de $86,9 \%$ a $55,3 \%$ e, considerando a presença de filhos, obtém-se quadro similar $^{11}$ (Sorj, 2006, p. 22). No entanto, não apenas a maternidade influencia negativamente o vínculo laboral feminino, também o exerce a própria conjugalidade. ${ }^{12}$ Os impactos dos fatores acima citados também podem ser observados em outros aspectos do vínculo laboral das mulheres, como a extensão da jornada de trabalho e seus rendimentos. As mulheres cujos filhos até seis anos freqüentam creche ou pré-escola possuem maiores níveis de rendimentos (acréscimo de cerca de $\mathrm{R} \$ 150$ ) e uma jornada de trabalho maior (em torno de 1,6 horas a mais, alcançando 35,8 $\mathrm{h} /$ semana), e o mesmo ocorre nos casos de filhos até três anos (rendimentos elevados em $\mathrm{R} \$ 143$ e uma hora de trabalho a mais, alcançando 35,1 h/semana) ou de filhos de quatro a seis anos (rendimentos maiores em $\mathrm{R} \$ 176,9$ e 2,8 horas de trabalho a mais, alcançando 35,4 h/semana) (Sorj, 2006, p. 42-44). Importante ressaltar ainda que tais dados, analisados segundo quatro grupos de renda, demonstram que há impactos positivos para as mães de todas as camadas sociais, porém, os mais signficativos são percebidos entre os mais pobres. Para os $25 \%$ mais pobres há crescimento de 38\% nos rendimentos das mães de filhos até três anos; e entre as mães de crianças entre quatro e seis anos, o crescimento é de $35 \%$ na renda das mais pobres enquanto entre as mais ricas é de apenas 14\% (Sorj, 2006, p. 44-47).

\footnotetext{
${ }^{11}$ A título de exemplo, observa-se que enquanto um homem chefe de uma família composta de cônjuge, filhos com idade inferior a 14 anos e sem parente, possui taxa de participação em torno de $97 \%$, no mesmo caso para as mulheres cônjuges, a taxa cai para apenas $60 \%$ - vale apontar ainda que a maior taxa de participação feminina se encontra entre as mulheres sozinhas $(86,9 \%)$ (Sorj, 2006, p. 22).

12 As mulheres chefes sem cônjuge e com filhos dependentes possuem taxa de participação no mercado de trabalho de $79 \%$, superior aos casos em que o homem está presente $(60 \%)$ (Sorj, 2006, p. 22).
} 
Desta forma, Sorj (2006, p. 44) aponta para a existência de um "círculo virtuoso no qual as mulheres que obtém um pouco mais de renda no trabalho colocam seus/as filhos na creche e a possibilidade de deixar os filhos na creche permite que elas ganhem mais no trabalho", e também para a dimensão democrática deste suporte de cuidados, já que este serviço é particularmente eficaz para as camadas mais pobres. A mesma autora aponta para a fraca legitimidade de tais políticas no Brasil, no entanto, observando documentos legais e programas governamentais, podemos levantar a hipótese de que o tema vem ganhando relevância, ainda que não seja possível avaliar se, de fato, tais formulações virão a alterar o quadro brasileiro, já que são de origem recente.

Em $1^{\circ}$ de janeiro de 2003 foi criada a Secretaria Especial de Políticas para as Mulheres da Presidência da República (SPM/ $\mathrm{PR})$, estabelecendo o compromisso de criação de políticas públicas que contribuam para a igualdade de gênero no País, por meio de uma proposta de transversalidade, contando com parcerias entre diversas instâncias governamentais. Em dezembro de 2004, como resultado da I Conferência Nacional de Políticas para as Mulheres, a SPM lançou o Plano Nacional de Políticas para as Mulheres (PNPM), com metas a serem cumpridas até o ano de 2007. Um dos eixos que compuseram o Plano foi a "educação inclusiva e não sexista", com objetivos relacionados à garantia de um sistema educacional não-discriminatório; incorporação das perspectivas de gênero, raça, etnia e orientação sexual na educacação formal e informal; bem como promover a visibilidade da contribuição das mulheres na construção da história da humanidade. A fim de alcançar tais objetivos, uma das ações previstas era ampliar em 12\% o número de crianças entre zero e seis anos de idade freqüentando creche ou pré-escola na rede pública. Quando do lançamento do PNPM, buscou-se assegurar o acompanhamento da evolução das metas previstas e, portanto, a Secretaria comprometeu-se em produzir relatórios de implementação. Segundo dados do relatório realizado em 2005, essa meta de ampliação da rede não foi atingida: 
a relação entre oferta pública e privada de creches permaneceu praticamente inalterada entre os anos de 2003 e $2005 .{ }^{13}$ A Tabela 3 aponta que a cobertura pública permanenceu restrita, com número reduzido de crianças na faixa de zero a seis anos de idade frequentando a educação infantil.

\section{Tabela 3 - Freqüência à creche e pré-escola da população de zero a 6 anos de idade}

\begin{tabular}{c|c|c|c|c}
\hline Ano & 2001 & 2002 & 2003 & 2004 \\
\hline População & 22.259 .308 & 21.688 .873 & 21.251 .114 & 21.083 .111 \\
\hline $\begin{array}{c}\text { Variação anual } \\
\text { da população }\end{array}$ & - & $-2,56 \%$ & $-2,02 \%$ & $-0,79 \%$ \\
\hline $\begin{array}{c}\text { População } \\
\text { freqüentando } \\
\text { creche ou pré }\end{array}$ & 4.692 .427 & 4.734 .870 & 4.980 .670 & 5.194 .129 \\
\hline $\begin{array}{c}\text { Variação anual } \\
\text { de população } \\
\text { freqüentando } \\
\text { creche ou pré- } \\
\text { escola }\end{array}$ & - & $0,90 \%$ & $5,19 \%$ & $4,29 \%$ \\
\hline $\begin{array}{c}\text { Percentagem } \\
\text { da população } \\
\text { freqüentando } \\
\text { creche ou pré- } \\
\text { escola }\end{array}$ & 21,1 & 21,8 & 23,4 & 24,6 \\
\hline
\end{tabular}

Fonte: PNAD/IBGE (citado por: Brasil. Presidência da República. SPM, 2006, p. 47).

Em 2007 ocorreu a II Conferência Nacional de Políticas para as Mulheres, cuja influência fez com que o PNPM sofresse alterações, dando origem ao II Plano Nacional de Políticas para Mulheres. Neste, a política de ampliação da rede pública de creches e pré-escolas foi retirada do item "Educação inclusiva e não sexista" e incorporada ao capítulo que trata da "Autonomia econômica e da igualdade no mundo do trabalho, com inclusão social". A justificativa para tal mudança de localização foi o

\footnotetext{
${ }_{13}$ Vale ressaltar que o Relatório foi produzido em 2005, um ano após o lançamento do PNPM, em 2004.
} 
reconhecimento de que tais ações são de "relevância impar para ampliar a autonomia econômica das mulheres e criar condições que permitam sua entrada no mercado formal de trabalho", conforme apontam os diversos estudos de gênero que tratam do tema. Desta forma, desvencilhou-se a ampliação da rede dos objetivos ligados à não-reprodução de esteriótipos de gênero, raça ou etnia, que permaneceram no capítulo destinado à "Educação inclusiva e não sexista" e associou-se a meta de "ampliação do acesso das mulheres ao mercado de trabalho" à "promoção da oferta de equipamentos sociais que contribuam para ampliar o tempo disponível das mulheres" (Brasil. Presidência da República. SPM, 2008, p. 39-42). No entanto, do lançamento do I PNPM, em 2004, para o II PNPM, em 2008, permaneceu inalterada a meta de ampliar "em 12\% o número de crianças entre zero e seis anos de idade freqentando creche ou pré-escola na rede pública", porém houve mudança na previsão para atingir tal objetivo - enquanto no primeiro a data limite era 2007, no segundo é até 2011 - apontando que poucas mudanças se efetivaram neste segmento de ensino desde 2004 até o ano corrente.

Um fato que pode ser apontado como uma conquista para o tema, é a inclusão da rede de creches e pré-escolas nos objetivos a serem atingidos pelo Fundo de Manutenção e Desenvolvimento da Educação Básica e de Valorização dos Profissionais da Educação (Fundeb) que atende toda a educação básica, regulamentado pela Lei no 11.494/2007, bem como a inclusão de creches comunitárias, confessionais ou filantrópicas sem fins lucrativos que tenham convênio com o Poder Público. Além disso, outro elemento importante é o Programa Nacional de Reestruturação e Aquisição de Equipamentos para a Rede Escolar Pública de Educação Infantil (Proinfância), instituído pela Resolução n ${ }^{\circ}$ 6, de 24 de abril de 2007, e que prevê, de acordo com dados do II PNPM, o investimento de R\$ 800 milhões entre 2007 e 2010. Nessa Resolução, o Governo Federal reconhece "a necessidade de promover ações supletivas e redistributivas, para a correção progressiva das disparidades de acesso e de 
garantia do padrão mínimo de qualidade de ensino"e afirma o propósito de "proporcionar à sociedade a melhoria da infra-estrutura da rede física escolar de Educação Infantil”. O Programa Proinfância prevê recursos financeiros destinados a investimentos em estabelecimentos deste segmento de ensino, concedendo assistência financeira ao Distrito Federal e aos municípios considerados prioritários, de acordo com os seguinte critérios:

a) populacional, priorizando municípios com maior população na faixa etária considerada, maior taxa de crescimento da população nesta faixa e maior concentração de população urbana;

b) educacional, priorizando municípios com menores taxas de defasagem idade-série no Ensino Fundamental e com maiores percentuais de professores com formação em nível superior; e

c) vulnerabilidade social, priorizando municípios com maiores percentuais de mulheres chefes de família, com maiores percentuais de jovens em situação de pobreza e com menores disponibilidades de recursos para financiamento da educação infantil.

Tais iniciativas são de fundamental importância para a legitimação do tema no País, e vale ressaltar que tais ações de auxílio financeiro visam suprir a carência de recursos municipais, buscando a viabilização das medidas previstas na Lei de Diretrizes e Bases da Educação (LDB).

A discussão sobre a inclusão desta cobertura no projeto da LDB também merece algumas considerações. Após cinco anos de estudos e debates, no ano de 1993, o projeto chegou ao Senado Federal para ser revisto e aprovado; havia dois textos em tramitação, um de autoria da Câmara dos Deputados e o Projeto Substitutivo apresentado pelo Senador Darcy Ribeiro, com semelhanças e diferenças. No entanto, ambos os textos adotavam 
o conceito de educação básica, que prevaleceu no texto final da LDB (Lei no 9.394/96) e que acabou por incluir a Educação Infantil como primeira etapa desta, fato considerado pelos educadores um avanço na valorização deste segmento de ensino. De acordo com Pereira e Teixeira (2002), a atual LDB representa uma opção conceital nova e ampliada da formação humana, garantindo uma percepção mais abrangente da função social da educação, prevendo sua vinculação ao mundo do trabalho e à prática social. Um dos componentes que marcariam essa maior abrangência conceitual, seria justamente a inclusão de etapas de escolarização e ampliação do número de anos; assim, a nova concepção passou a incluir a Educação Infantil, Ensinos Fundamental e Médio, contemplando uma escolarização desde zero ano de idade até o final da última etapa (Pereira; Teixeira, 2002, p. 89-90). Porém vale ressaltar que a LDB prevê como ensino obrigatório, apenas o Ensino Fundamental, com duração mínima de nove anos, que deve ter oferta prioritária, e que, a partir da aprovação da Lei no 11.114, de 16 de maio de 2005, este segmento passou a ter início aos seis, e não mais aos sete anos de idade, ampliando sua cobertura.

Os autores apontam que houve uma mudança clara na concepção da Educação Infantil, configurando-se como primeira etapa educacional e objetivando o desenvolvimento integral de crianças nessa faixa etária e, assim, instituiu-se o atendimento em creches para a idade de zero a três anos e pré-escola para de quatro a seis anos. Sinalizam ainda que priorizar o desenvolvimento infantil representou uma superação da noção de pré-escola como supressão de carências de crianças oriundas das classes populares principalmente, e que se destinaria a uma espécie de "preparação para a escola regular”. A ênfase dada à dimensão pedagógica do atendimento, visando ao crescimento multidimensional de crianças nessa faixa, significaria também uma “(...) superação da visão equivocada assistencialista - restrita à função de "guarda de crianças" - que tem caracterizado as ações governamentais no setor, ainda que dispersas e descontínuas" (Pereira; Teixeira, 2002, p. 91). No entanto, vale marcar 
que a inclusão deste segmento foi alvo de grandes polêmicas e que, em algumas versões de relatórios no Senado Federal, ele chegou a ser retirado do âmbito da educação básica (p. 91-92).

Por fim, a LDB incluiu a Educação Infantil em sua concepção de Educação Básica, mas atribuiu a função de cobertura ao poder público municipal. Pereira e Teixeira (2002, p. 97) colocam que, entre outros fatores relacionados ao financiamento, foram eliminados do texto os dispositivos referentes à criação do salário-creche e que a lei, embora amplie a responsabilidade do Estado no que se refere à educação, permitiu a evasão de recursos públicos destinados a este fim; apontam ainda que $\mathrm{O}$ Brasil apresenta um dos menores índices de investimento na área, mesmo se comparado com outros países latino-americanos. Assim coube ao poder público municipal, segundo a Lei no 9.394/96, art. $4^{\circ}$, inciso IV,

Oferecer a educação infantil em creches e pré-escolas, e, com prioridade, o ensino fundamental, permitida a atuação em outros níveis de ensino somente quando estiverem atendidas plenamente as necessidades de sua área de competência e com recursos acima dos percentuais mínimos vinculados pela Constituição Federal à manutenção e desenvolvimento do ensino.

Tal indicação, segundo especialistas, acabou dificultando o oferecimento desse atendimento, não só em termos de alocacão de recursos, mas também pelo fato de o município ter recebido atribuições e responsabilidades para as quais, até então, não tinha experiência, tornando-se de fundamental importância a ampliação de conhecimentos no que se refere à legislação educacional, a fim de se alcançar uma gestão eficiente (Gracindo, 2002). Logo, iniciativas recentes como o ProInfância, a inclusão desse segmento nos recursos do Fundeb, e a própria indicação para o atendimento contida nos dois Planos Nacionais de Políticas para Mulheres são de importância ímpar na valorização da Educação Infantil e nas possibilidades de ampliação dos recursos a ela destinados. 
A ampliação da cobertura também está prevista nos últimos dois Planos Plurianuais (PPA) que estabelecem diretrizes, objetivos e metas da administração pública federal e orientam a elaboração do Orçamento da União para quatro anos. ${ }^{14} \mathrm{Na}$ gestão do Governo Lula foram elaborados o PPA 2004-2007 e PPA 2008-2011, incluindo o primeiro ano do governo seguinte; pelo sítio do Ministério do Planejamento é possível ter acesso também aos PPAs de 1996-1999 e 2000-2003, da gestão de Fernando Henrique Cardoso. Devido às diferenças estruturais entre os planos e os limites deste trabalho, optamos por não utilizar tais dados em nossa análise, porém, como sugestão, podemos apontar que somando os recursos destinados aos programas com objetivos ligados à ampliação de acesso à escola, e comparando os respectivos orçamentos no PPA 2000-2003 (governo FHC) e no PPA 2008-2011 (governo Lula), observamos grandes diferenças orçamentárias. No primeiro obtemos a cifra de $\mathrm{R} \$ 22,2$ bilhões (somando os valores dos Programas "Desenvolvimento do Ensino Médio”, R \$ 1,3 bilhão; “Toda Criança na Escola”, R\$14,3 bilhões; "Escola de Qualidade para Todos", R \$ 4,5 bilhões; "Atenção à Criança”, R $\$ 1,7$ bilhões), enquanto no segundo o valor fica em torno de R \$ 49, 7 bilhões. Dada a magnitude da diferença, é possível supor que o setor tenha adquirido maior atenção nos planos mais recentes, como apontamos em seguida.

No PPA 2004-2007, estava previsto um programa destinado ao Desenvolvimento da Educação Infantil, com um público-alvo de crianças até seis anos, objetivando a "ampliação do atendimento de crianças até seis anos de idade na Educação Infantil com qualidade" que previa o aumento das taxas de: (a) freqüência à escola da população de zero a três anos; e (b) frequência à escola da população de quatro a seis anos. No PPA 2008-2011, como parte

\footnotetext{
${ }^{14}$ De acordo com dados do sítio do Ministério do Planejamento, Orçamento e Gestão, "Elaborar um Plano Plurianual é decidir quais são os investimentos mais importantes dentro de um projeto de desenvolvimento". De acordo com o sítio, o PPA foi instituído pela Constituição Federal de 1988 (artigo 165, parágrafo $1^{\circ}$ ), mas o Plano de Metas (crescer 50 anos em 5), do Governo de Juscelino Kubitschek (1956-1961) pode ser considerado um exemplo deste tipo de política governamental.
} 
do Programa "Brasil Escolarizado" sob a responsabilidade do Ministério da Educação (MEC) e com o objetivo de "contribuirpara a universalização da Educação Básica, assegurando eqüidade nas condições de acesso e permanência", estão previstas as mesmas ações. A Tabela 4 sistematiza os dados disponíveis em ambos os planos (índices de referência e os respectivos anos; metas e os respectivos anos).

\section{Tabela 4 - Previsão para o atendimento na Educação Infantil - 2004-2011}

\begin{tabular}{|c|c|c|c|c|}
\hline \multirow[t]{2}{*}{$\begin{array}{l}\text { Plano pluri- } \\
\text { anual }\end{array}$} & \multicolumn{2}{|c|}{$\begin{array}{c}\text { Taxa de freqüência à creche } \\
\text { da população na faixa etária } \\
\text { de } 0-3 \text { anos }\end{array}$} & \multicolumn{2}{|c|}{$\begin{array}{c}\text { Taxa de frequência à pré- } \\
\text { escola da população na faixa } \\
\text { etária de } \\
4-6 \text { anos }\end{array}$} \\
\hline & $\begin{array}{l}\text { Índice de } \\
\text { referência }\end{array}$ & Previsão & $\begin{array}{l}\text { Índice de } \\
\text { referência }\end{array}$ & Previsão \\
\hline $\begin{array}{c}\text { PPA 2004- } \\
2007\end{array}$ & 11,7\% (dez. 2002) & $\begin{array}{l}31,4 \% \\
(2007)\end{array}$ & 67\% (dez. 2002) & $\begin{array}{l}77 \% \\
(2007)\end{array}$ \\
\hline $\begin{array}{c}\text { PPA 2008- } \\
2011\end{array}$ & $13 \%$ (set. 2005) & $\begin{array}{l}54,4 \% \\
(2011)\end{array}$ & $62,9 \%$ (set. 2005) & $\begin{array}{l}87,5 \% \\
(2011)\end{array}$ \\
\hline
\end{tabular}

É possível obervar que as metas previstas no PPA 20042007 não apenas não foram alcançadas, como houve redução na taxa de frequência à pré-escola da população na faixa etária de quatro a seis anos. Uma hipótese para tal redução é a dificuldade de conquista de vaga pública nos arredores da residência e/ou trabalho, o que, por vezes, acaba impedindo as famílias de fazerem uso do serviço, por dificuldades de deslocamento tanto em termos de tempo quanto de custo de transporte - já que este é um serviço amplamente desejado, como comprovam as "filas de espera" por vagas na educação infantil em inúmeras prefeituras. ${ }^{15}$

Por fim, em termos legais, outro dado que merece destaque, é o veto dado pela Presidência da República, em 1997, ao Projeto de Lei no 2.802 de 1992 ( $n^{\circ} 112 / 92$ no Senado Federal) - que

\footnotetext{
${ }^{15}$ Através de pesquisa em sítios de jornais de grande circulação, encontramos inúmeras reportagens sobre as "filas" e os tempos de espera - que em alguns casos demora anos - mesmo tendo como referência apenas o ano de 2008.
} 
pode ser apontado como uma batalha perdida com relação ao tema, mas, devido aos limites deste trabalho, sua análise não será viável. Esse projeto de lei buscava estender a assistência técnica e educacional - que na Consolidação das Leis Trabalhistas (CLT) está prevista para crianças até seis meses -, para até seis anos de idade em empresas que tivessem, no mínimo, 30 empregados com mais de dezesseis anos. $\mathrm{O}$ texto previa que tal exigência poderia ser cumprida por intermédio de creches e pré-escolas mantidas diretamente pela empresa ou por convênios com outras entidades públicas ou privadas. Na ocasião, a Presidência da República argumentou que tal modificação geraria uma "brutal elevação dos encargos de natureza social que já pesam sobre a atividade empresarial” e consequente discriminação em relação à mão-de-obra feminina (Mensagem no 1.645, 30 de dezembro de1997).

\section{Considerações finais: "chegaremos lá"?}

Observamos que, a partir de um quadro geral, o tema da equidade de gênero e da conciliação entre trabalho e vida familiar no Brasil tem alcançado a esfera pública com mais vigor nos últimos anos. Isto pode ser atribuído, em grande parte, à criação da Secretaria de Políticas para Mulheres e aos planos por ela estabelecidos e que têm contribuído em muito para tais modificações. A elaboração dos planos resultou das conferências que prevêm a participação de membros do poder público, de organizações da sociedade civil e do empesariado.

As alterações estabelecidas pela atual LDB, juntamente com as ações governamentais previstas, caso sejam de fato cumpridas - o que não aconteceu no período de referência para o I PNPM - podem colaborar, efetivamente, para a ampliação do chamado "tempo disponível" das mulheres, principalmente num contexto de elevação das famílias monoparentais femininas. No entanto, a forte crítica dos educadores à concepção da educação infantil como "equivocada visão assistencialista, restrita à função de 
'guarda de crianças"' (Pereira; Teixeira, 2002, p. 91), aponta para uma distância entre os objetivos dos educadores e os objetivos dos movimentos feministas: ainda que seja importante a percepção deste segmento como etapa do desenvolvimento do indíviduo, sua função de auxílio nos cuidados também deve ser considerada. De fato, a relocalização da política de cobertura de creches no II PNPM no item de "ampliação do acesso das mulheres ao mercado de trabalho" é uma clara defesa de que a oferta de equipamentos sociais pode contribuir, e muito, para a ampliação do tempo disponível das mulheres.

Essa cobertura de serviços sociais públicos adquire importância ainda maior se considerarmos o contexto econômico e social de nosso país. Conforme apontamos, em países de precariedade econômica, a solidariedade familiar acaba por preencher a ausência de serviços sociais - o que coloca as famílias que não têm a possibilidade de contar com tal auxílio em situação de extrema desvantagem. E, relembrando as palavras de Bruschini (2007, p. 56), é possível projetar que, à medida que as mulheres permanecem por mais tempo no mercado de trabalho, logo se chegará a uma geração em que os avós e, principalmente as avós, não estarão disponíveis para exercer esse auxílio. Ainda que com uma taxa de atividade inferior à dos homens, as mulheres correspondiam a 44,4\% de atividade em 2002 segundo o IBGE, e a $42 \%$ da população economicamente ativa (PEA) em 2003 (Freire, 2007, p.12). Poderão as famílias abrir mão da contribuição feminina? Conforme já afirmado, em contextos de altos índices de desemprego e baixos salários, essa contribuição tem sido essencial para manter as famílias longe da linha de pobreza, além de ser fator importante também nas classes médias para a manutenção dos níveis de rendimento familiar, e não só em nosso país.

De acordo com Jenson (1997), as políticas destinadas a cuidados devem ter como ponto de partida em sua formulação três 
questões: Who cares? Who pays? How is it provided? ${ }^{16}$ (Jenson, 1997). Partindo desta premissa, observamos que, no Brasil, as mulheres é que cuidam, as famílias pagam e o serviço provém, em grande parte, da solidariedade familiar e da manutenção da tradicional divisão sexual do trabalho. A atividade remunerada feminina, desejada por ambos sexos, ainda é percebida como incompatível com a maternidade, principalmente na primeira infância, conforme comprovaram os dados de Araújo e Scalon (2005). Sem dúvida alguma, as políticas destinadas à conciliação do trabalho com a vida familiar exercem influência decisiva na percepção de homens e mulheres acerca do tema, e podem contribuir para a construção de um imaginário coletivo que conceba como viável a manutenção das mulheres e das mães no mercado de trabalho sem que isso represente uma ruptura com o papel de mãe ou acarrete sofrimento para as crianças. Numa realidade social em que tal divisão sexual está fortemente enraizada, a emancipação financeira feminina pressupõe abrir mão ou postergar a maternidade, ou submeter-se a tais condições.

O Estado de Bem-Estar brasileiro, consagrador de desigualdades e condicionado a uma hierarquia de classes, parece não ser distintivo neste aspecto: tanto as mães que procuram vagas em creches públicas, quanto as que podem optar pela rede privada sofrem com a atual carência de serviços disponíveis. Os "sorteios de vagas" e as "filas de espera" para mães que querem matricular seus filhos em "boas creches" - seja as que estão mais próximas da residência, seja as que possuem melhor projeto pedagógico, públicas ou privadas - são desagradáveis, requerem paciência e não distinguem classe social. Basta uma "busca" na internet para que isso se confirme: tanto nos jornais de grande circulação são inúmeras as reportagens e denúncias a esse respeito, quanto em

\footnotetext{
${ }^{16}$ Jenson (1997), em crítica a Lewis, aponta que o tratamento do tema a partir das noções de trabalho remunerado e não-remunerado, não evidencia a questão do "cuidado" e propõe essas três questões para repensar políticas de welfare state, ressaltando a questão dos "cuidados" como eixo principal na formulação de políticas públicas que visam auxiliar as famílias na tarefa de compatibilizar trabalho e família, atentando para as desigualdades de gênero tanto no núcleo familiar quanto no mercado de trabalho.
} 
sítios de relacionamento destinados às mães - não é à toa que existe o Movimento das Mães sem Creche no município de São Paulo. Assim, para aquelas mulheres que percebem o acompanhamento da educação e do crescimento de uma criança como "a maior alegria da vida" e acreditam que "exercer atividade profissional é importante para as pessoas se sentirem realizadas e felizes", ainda há muito por fazer. Logo, ainda que tenhamos apontado recentes avanços no nível de discussão e de formulação de políticas públicas, é preciso acompanhar as ações e estimular debates sobre o tema, bem como o da "paternidade responsável". Como afirma EspingAndersen (2002), que se "masculinize a trajetória feminina e se feminilize a masculina".

\section{Referências}

ABRAMO, Laís. A situação da mulher latino-americana: o mercado de trabalho no contexto da reestruturação. In: DELGADO, D. G.; CAPPELLIN, Paola; SOARES, Vera (Orgs.). Mulher e trabalho: experiências de ação afirmativa. São Paulo: Boitempo, 2000. p. 111134.

ARRIAGADA, Irma. Estruturas Familiares, Trabalho e Bem-Estar na América Latina. In: ARAÚJO, Clara; SCALON, Celi; PICANÇO, Felícia. Novas conciliações e antigas tensões? São Paulo: Edusc, 2007. p. 223-265.

ARAÚJO, Clara; SCALON, Celi; PICANÇO, Felícia. Gênero, família e trabalho: conservadores e satisfeitos? In: ARAÚJO, Clara; SCALON, Celi; PICANÇO, Felícia. Novas conciliações e antigas tensões? São Paulo: Edusc, 2007. p. 269-328.

ARAÚJO, Clara; SCALON, Celi. Percepções e atitudes de mulheres e homens sobre a conciliação entre família e trabalho pago no Brasil. In: ARAÚJO, Clara; SCALON, Celi (Orgs.). Gênero, familia e trabalho no Brasil. Rio de Janeiro: FGV Editora, 2005. p. 15-77.

ASTELARRA, Judith. Políticas Públicas e Divisão entre Trabalho Remunerado e Não Remunerado na Espanha. In: ARAÚJO, Clara; SCALON, Celi; PICANÇO, Felícia. Novas conciliações e antigas tensões? São Paulo: Edusc, 2007. p. 59-95 
BRASIL. Fundo Nacional de Desenvolvimento da Educação (FNDE). Programa Nacional de Reestruturação e Aparelhagem da Rede Escolar Pública de Educação Infantil (ProInfancia). Disponível em: <http:// www.fnde.gov.br/home/index.jsp?arquivo=pro_infancia.html $>$.

- Resolução CD/FNDE/nº06 de 24 de abril de 2007. Estabelece as orientações e diretrizes para execução e assistência financeira suplementar ao Programa Nacional de Reestruturação e Aquisição de Equipamentos para a Rede Escolar Pública de Educação Infantil - ProInfância.

BRASIL. Lei $n^{\circ}$ 9.394, 20 de dezembro de 1996. Estabelece as diretrizes e bases da educação nacional. Disponível em: < http://portal.mec. gov.br/sesu/arquivos/pdf/lei9394.pdf>.

. Lei $n^{\circ} 11.114$, de 16 de maio de 2005. Mensagem de veto. Altera os arts. $6^{\circ}, 30,32$ e 87 da Lei n ${ }^{\circ}$ 9.394, de 20 de dezembro de 1996, com o objetivo de tornar obrigatório o início do ensino fundamental aos seis anos de idade. Disponível em: <http:/ /www.planalto.gov. br/ccivil_03/_Ato2004-2006/2005/Lei/L11114.htm>.

. Lei no 11.494, de 20 de junbo de 2007. Regulamenta o Fundo de Manutenção e Desenvolvimento da Educação Básica e de Valorização dos Profissionais da Educação - FUNDEB. Diario Oficial da União. Brasília, 21 jun. 2007. Disponível em: $<$ https://conlegis.planejamento.gov.br/conlegis/legislacao/ atoNormativoDetalhesPub.htm?id $=5686>$.

. Mensagem n 1.645, de 30 de dezembro de 1997. Disponível em: <http:/ /www.planalto.gov.br/CCIVIL/VETO_TOTAL/1997/ Mv1645-97.htm>.

BRASIL. Ministério do Planejamento, Orçamento e Gestão. Plano plurianual: relatório anual de avaliação [exercícios de 2000 a 2008]. Disponível em: <http://www.planejamento.gov.br/noticia.asp?p $=$ not $\& \operatorname{cod}=197 \& \mathrm{cat}=155 \& \mathrm{sec}=10>$.

. Plano plurianual 2000-2003 [Avança Brasil]. Disponível em: http://www.abrasil.gov.br/

- Plano plurianual 2004-2007 [Plano Brasil: Participação e Inclusão]. Disponível em: <http://www.planobrasil.gov.br/>. 
BRASIL. Plano plurianual 2008-2011. Volume II: Projeto de Lei e Anexos; Anexo I: Programas de Governo Finalísticos; Anexo II: Programas de Governo Apoio às Políticas Públicas e Áreas Especiais. Disponível em: <http://www.planejamento.gov.br/ noticia.asp? $\mathrm{p}=$ not $\& \operatorname{cod}=191 \& \mathrm{cat}=155 \& \sec =10>$.

BRASIL. Presidência da República. Secretaria Especial de Políticas para as Mulheres (SPM). Plano Nacional de Politicas para as Mulheres. Brasília, 2004. . Plano Nacional de Politicas para as Mulheres. Brasília, 2008.

- Plano Nacional de Políticas para as Mulheres: relatório de implementação 2005. Brasília, 2006. Disponível em: $<$ http://200.130.7.5/spmu/docs/pnpm_relatorio.pdf>.

BRUSCHINI, Cristina. Trabalho doméstico: inatividade econômica ou trabalho não remunerado? In: ARAÚJO, Clara; SCALON, Celi; PICANÇO, Felícia. Novas conciliacõoes e antigas tensões? São Paulo: Edusc, 2007. p. 21-58.

ESPING-ANDERSEN, Gösta. Why we need a new Welfare State. Oxford: Oxford Univerity Press, 2002. Cap. I e III.

FREIRE, Nilcéia. Conferência de abertura: seminário gênero, família e trabalho em perspectiva comparada. In: ARAÚJO, Clara; SCALON; Celi; PICANÇO, Felícia. Novas conciliaçoes e antigas tensões? São Paulo: EDUSC, 2007. p. 11-18.

GORNICK Janet C.; MEYERS, Marcia K. Regimes de bem-estar social com relação a trabalho remunerado e cuidados. In: ARAÚJO, Clara; SCALON, Celi; PICANÇO, Felícia. Novas conciliações e antigas tensões? São Paulo: Edusc, 2007. p. 191-222

GRACINDO, Regina Vinhaes. Os sistemas muncipais de ensino e a nova LDB: limites e possibilidades. In: BRZENZINSKI, Iria (org.). LDB interpretada: diversos olhares se entrecruzam. São Paulo: Cortez, 2002. p. 211-232

JENSON, Jane. Who cares? Gender and welfare regimes. Social Politics, v. 4, n. 2, p. 77-99, 1997.

LEWIS, Jane. The decline of the male breadwinner model: The implications for work and care. Social Politics, v. 8, n. 2, p. 152-170, 2001. 
LOBO, Heloísa Helena O.; DIDONET, Vital. LDB: últimos passos no Congresso Nacional. In: BRZENZINSKI, Iria (Org.). LDB interpretada: diversos olhares se entrecruzam. São Paulo: Cortez, 2002. p. 43-68.

PEIXOTO, Clarice Ehlers. Solidariedade familiar intergeracional. In: ARAÚJO, Clara; SCALON, Celi (Orgs.). Gênero, família e trabalho no Brasil. Rio de Janeiro: FGV Editora, 2005. p. 225-240.

PEREIRA, Eva Waisros; TEIXEIRA, Zuleide Araújo. A educação básica redimensionada. In: BRZENZINSKI, Iria (Org.). LDB Interpretada: diversos olhares se entrecruzam. São Paulo: Cortez, 2002. p. 87-109

RODRIGUES, Almira; CORTÊS, Iáris (Orgs.). Os direitos das mulheres na legislação brasileira pós-constituinte. Brasília: Letras Livres, Centro Feminista de Estudos e Assessoria (Cfemea). 2006.

SORJ, Bila. Legislação trabalhista, políticas públicas e igualdade de gênero. In: SORJ, Bila; YANNOULAS, Silvia. Perspectivas e críticas feministas sobre as reformas trabalhista e sindical. Brasília: CFMEA, 2006. p. $15-50$

SORJ, Bila; FONTES, Adriana; MACHADO, Danielle C. Políticas e práticas de conciliação entre família e trabalho no Brasil. Cadernos de Pesquisa, São Paulo, v.37, n.132, p. 573-594, set./dez. 2007.

VELHO, Gilberto. Individualismo e cultura: notas para uma Antropologia da sociedade contemporânea. Rio de Janeiro: Zahar, 2004.

Submetido em 15 de setembro de 2008 e aceito em 19 novembro de 2008 